\title{
DEFICIENCIA DE GLUCOSA 6-FOSFATO DESHIDROGENASA EN COLOMBIA: MEMORIAS DE 22 AÑOS DE TAMIZAJE DE ALTO RIESGO
}

\author{
ALFREDO URIBE ARDILA * BSc. MSc; y PhD. EN CIENCIAS BIOLÓGICAS \\ * Director, Centro de Investigaciones en Bioquímica (CIBI), Departamento de Ciencias Biológicas, \\ Universidad de Los Andes. \\ Centro de Investigaciones en Bioquímica (CIBI) de la Universidad de los Andes, \\ Calle 1 No. 18A - 10, Edificio M-Tercer Piso, Bogotá - Colombia \\ "Correspondencia: Alfredo Uribe Ardila, jeuribe@uniandes.edu.co
}

Recibido: 22 Mayo 2017 Aceptado: 30 Junio 2017

\section{RESUMEN}

La deficiencia de la Glucosa 6 Fosfato Deshidrogenasa es un desorden hereditario del metabolismo ligado al cromosoma X, considerada como la enfermedad metabólica de mayor frecuencia a nivel mundial con más de 400 millones de individuos afectados, es la causa más común de anemia hemolítica no autoinmune de origen metabólico. La prevalencia calculada para Colombia según la organización mundial de la salud se encuentra entre $3-7 \%$, pero los reportes de estudios poblacionales son escasos, creando la necesidad de incluir esta deficiencia en un programa de tamizaje neonatal, más cuando aproximadamente un $11 \%$ de la población es afrodescendiente, que sin contar con el mestizaje, puede ofrecer una frecuencia mayor de la deficiencia en ciertas regiones del país.

El presente estudio brinda entonces, una panorámica general de la prevalencia de esta enzimopatía eritrocitaria, en población con anemia hemolítica crónica o episódica de naturaleza no inmune, procedentes de diferentes lugares del territorio nacional. Comprende la valoración de 3837 muestras durante el periodo 1998 al 2016, un total de 1801 controles y 2036 individuos (982 hombres/1054 mujeres, Rango de edad: 1 semana a 91 años) con hallazgos sugerentes de esta condición metabólica.

Los resultados encontrados, ofrecen una prevalencia del $7 \%$ de la deficiencia con grados variables de actividad residual. El rango general de los grupos control osciló entre 3,31 - 9,98 UI/gr HB, contrastante contra el grupo de afectados $(\mathrm{n}=144)$ que ofreció un valor de 0,0 - 2,97, el $67 \%(\mathrm{n}=96)$ correspondiente a varones afectados. Estos hallazgos evidencian la importancia de incluir dentro de un programa de detección neonatal, esta enzimopatía eritrocitaria.

Palabras claves: Anemia hemolítica; Glucosa-6-fosfato deshidrogenasa; Estrés oxidativo eritrocitario; Enzimopatías eritrocitarias. 


\title{
GLUCOSE-6-PHOSPHATE DEHYDROGENASE DEFICIENCY IN COLOMBIA: MEMORIES OF TWENTY-TWO YEARS OF HIGH RISK SCREENING
}

\begin{abstract}
Deficiency of Glucose-6 -Phosphate Dehydrogenase is an inherited disorder of X-linked metabolism, as the metabolic disease of the world's largest frequency with more than 400 million affected individuals, is the most common cause of non-autoimmune hemolytic anemia of metabolic origin. The prevalence calculated for Colombia according to the world health organization is between 3 and $7 \%$, but the reports of population studies are scarce, creating the need to include this deficiency in a neonatal screening program, closer to $11 \%$ population is Afro-descendant that without the miscegenation, can offer a greater frequency of deficiency in certain regions of the country.

The present study provides an overview of the prevalence of erythrocyte enzyme disease in the population with chronic or episodic hemolytic anemia of non-immune nature from different parts of the national territory. It comprises the evaluation of 3837 samples during the period 1998 to 2016, a total of 1801 controls and 2036 individuals (982 men / 1054 women, age range: 1 week to 91 years) with suggestive findings of this metabolic condition.

The results found, offer a prevalence of $7 \%$ of the deficiency with variable degrees of residual activity. The overall range of the control groups ranged from 3.31 - $9.98 \mathrm{IU} / \mathrm{g} \mathrm{HB}$, contrasting against the group of affected $(\mathrm{n}=$ 144) who offered a value of $0.0-2.97,67 \%=96$ ) corresponds to affected males. These findings highlight the importance of including this erythrocyte enzyme disease in a neonatal screening program.
\end{abstract}

Key Words: Hemolytic anemia; Glucose 6-phosphate dehydrogenase; erythrocyte oxidative stress; Erythroenzymopathies.

\section{DEFICIÊNCIA DE DEHIDROGENASE DE GLUCOSE-6-FOSFATO NA COLÔMBIA: MEMÓRIAS DE VINTE E DOIS ANOS DE PEDAGEM DE ALTO RISCO}

\author{
RESUMO
}

A deficiência de glucose-6-fosfato desidrogenase é uma desordem hereditária do metabolismo ligado ao X, como a doença metabólica da maior freqüência do mundo com mais de 400 milhões de indivíduos afetados, é a causa mais comum de anemia hemolítica não autoimune de origem metabólica. A prevalência calculada para a Colômbia de acordo com a organização mundial de saúde é entre 3 e 7\%, mas os relatórios de estudos populacionais são escassos, criando a necessidade de incluir esta deficiência em um programa de triagem neonatal, perto de $11 \%$ a população é afro-descendente que sem a miscigenação, pode oferecer uma maior frequência de deficiência em certas regiões do país.

O presente estudo fornece uma visão geral da prevalência de doença enzimática de eritrócitos na população com anemia hemolítica crônica ou episódica de natureza não imune de diferentes partes do território nacional. Compreende a avaliação de 3837 amostras durante o período de 1998 a 2016, um total de 1801 controles e 
2036 indivíduos (982 homens / 1054 mulheres, faixa etária: 1 semana a 91 anos) com achados sugestivos desta condição metabólica.

Os resultados encontrados, oferecem uma prevalência de 7\% da deficiência com graus variáveis de atividade residual. O intervalo geral dos grupos de controle variou de 3,31 a 9,98 UI / g de HB, contrastando com o grupo de afetados $(n=144)$ que ofereceu um valor de $0,0-297,67 \%=96)$ corresponde a machos afetados. Esses achados destacam a importância de incluir esta doença enzimática de eritrócitos em um programa de triagem neonatal.

Palavras-chave: anemia hemolítica; Glucose 6-fosfato desidrogenase; Estresse oxidativo de eritrócitos; Eritroenzimopatias.

\section{Introducción}

La vía de las pentosas fosfato (VPF) constituye una de las derivaciones más importantes de la vía glucolítica, una alternativa metabólica que se orienta fundamentalmente a la sintesis del NADPH, compuesto involucrado en secuencias anabólicas reductivas y a la generación de las pentosas necesarias para la conformación de los ácidos nucleicos $(1,2)$.

La VPF es esencialmente una estrategia anabólica que, aunque no se relaciona a los procesos generadores de energía de la célula, su importancia es crítica en la biosíntesis de metabolitos intermedios que apoyan la producción celular de ácidos grasos, esteroides y la renovación de la capacidad antioxidante del glutatión que favorece a la membrana celular de los efectos nocivos del peróxido de hidrogeno (3).

En forma global, para los diversos tejidos corporales son la VPF y la glucolisis, fuentes importantes de metabolitos intermediarios y energía respectivamente, pero para los glóbulos rojos son fundamentales, en razón, a que esta población celular no tiene mitocondrias o estructura nuclear, compartimentos que suplen de energía y renovación proteica a otras células, quedando entonces bajo una estricta dependencia de estas estrategias metabólicas para su funcionalidad y supervivencia (2).

Esta subordinación metabólica que caracteriza a los glóbulos rojos, conlleva una seria implicación relacionada a la dependencia de la correcta acción catalítica de aproximadamente 20 enzimas (Figura 1), moléculas que no son renovables dentro de la misma célula dada la ausencia de núcleo y cuya deficiencia son la causa de un grupo de trastornos hemolíticos agrupados como enzimopatías eritrocitarias, un grupo de alteraciones de amplia expresión fenotípica que incluyen grados diversos de anemia hemolítica no esferocítica e hiperbilirrubinemia, entre otras manifestaciones $(2,4)$.
Las enzimopatías eritrocitarias, abarcan un número importante de enfermedades metabólicas que afectan la vida media de los glóbulos rojos expresándose como una anemia hemolítica generalmente de carácter episódico no relacionada a procesos de autoinmunidad sino a fenómenos de estrés oxidativo. Dentro de este grupo de anormalidades Bioquímicas, se encuentra la deficiencia de Glucosa-6-fosfato Deshidrogenasa (G6PD: EC1.1.1.49), considerada una de las alteraciones enzimáticas de mayor prevalencia a nivel mundial $(6,7)$.

La G6PD es un complejo enzimático de localización citoplásmica y distribución sistémica, que juega un papel esencial en el metabolismo celular al dar comienzo al ciclo de las pentosas, convirtiendo la glucosa 6 fosfato proveniente de la vía Glucolítica a 6 Fosfogluconato (Ver figura 1), una acción catalítica que involucra la generación Nicotin Adenin Dinucleotido Fosfato en su forma reducida (NADPH), un cofactor fundamental en diversas rutas biosintéticas, pero imprescindible en los procesos de reducción enzimática del glutatión eritrocitario, un tripeptido que actúa como un elemento amortiguador de grupos sulfidrilos, que mantienen en estado reducido las unidades aminoacídicas de cisteína de la hemoglobina y otros elementos proteicos de los hematíes, aliviando el estrés oxidativo ya antes descrito. En consecuencia, las células con bajo nivel de Glutatión reducido por deficiencia de este componente muestran mayor susceptibilidad al fenómeno hemolítico característico de esta deficiencia enzimática $(2,8)$.

El gen de la G6PD que fue secuenciado en el año de 1986, se encuentra localizado en la región telomérica del brazo largo del Cromosoma X (Xq28), consiste de 12 intrones y 13 exones que codifican para una secuencia de 515 aminoácidos (Ver Figura 2A). La literatura mundial ha documentado 186 mutaciones hasta la fecha, donde el 85,4 \% corresponden a cambios puntuales que se distribuyen en todos los exones que codifican la enzima, con una mayor frecuencia a nivel del exón 10 (Ver Figura 2B) $(9,10)$. 
Ruta Embden-Meyerhof

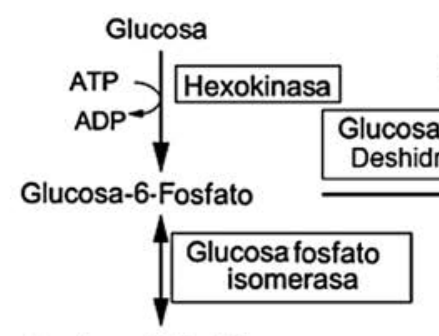

Fructosa-6-Fosfato

$$
\text { ATP } D \text { Fosfofructokinasa }
$$

Fructose-1,6-Fosfato

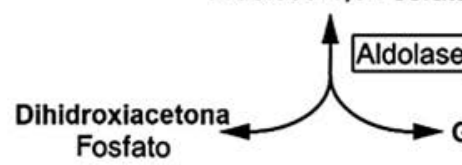

Aldolase

\section{Derivacion Hexosa-Monofosfato}

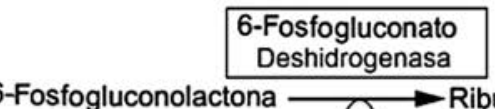

6-Fosfogluconolactona $\longrightarrow$ Ribulose-5-Fosfato

6-Fosfogluconato

NADP NADPH

NADP NAD

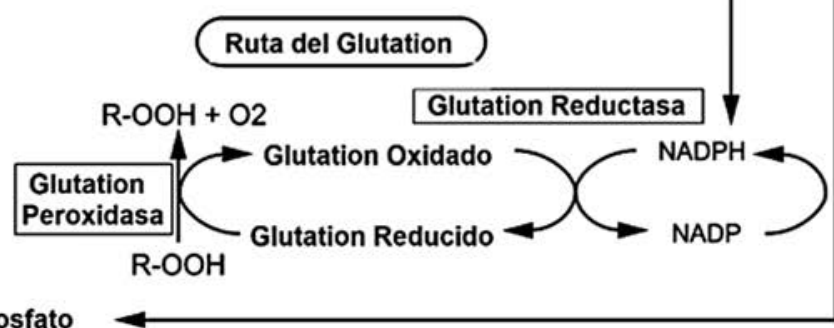

Gliceraldehido 3-Fosfato

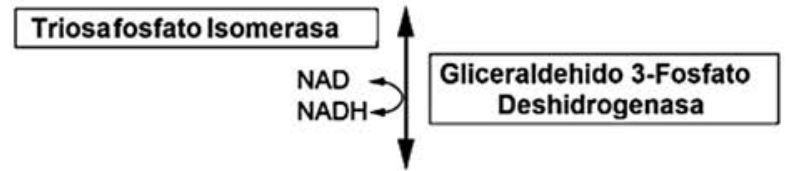

Derivacion Rapoport-Luebering

1,3-Bifosfoglicerato

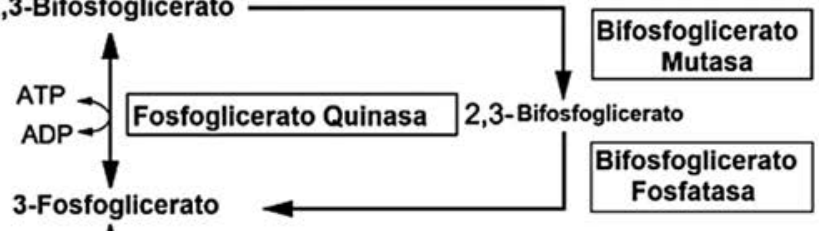

3-Fosfoglicerato

Fosfatasa
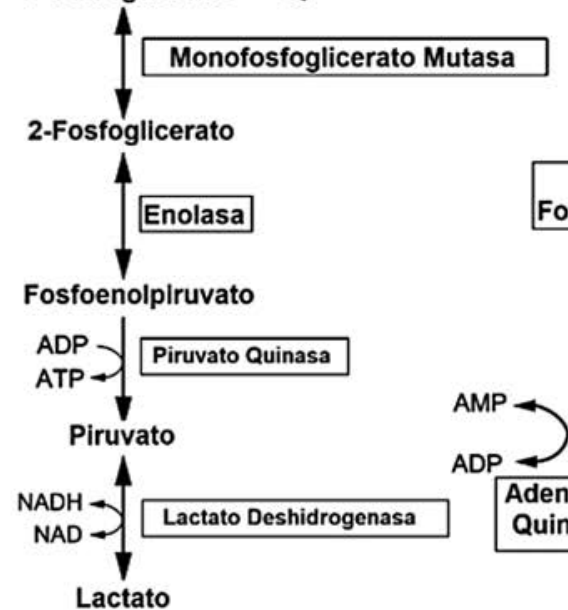

Adenina

Metabolismo de Nucleotidos
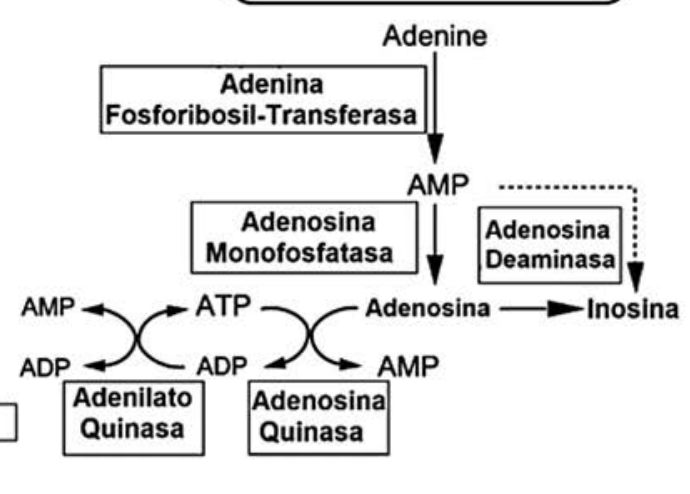

5'-nucleotidase

5'-ribonucleotide $\longrightarrow$ ribonucleoside

Figura 1. Descripción de las rutas metabólicas principales de las células eritrocitarias.

Tomado y modificado de Koralkova, P. et al., 2014 (5) 
(A)

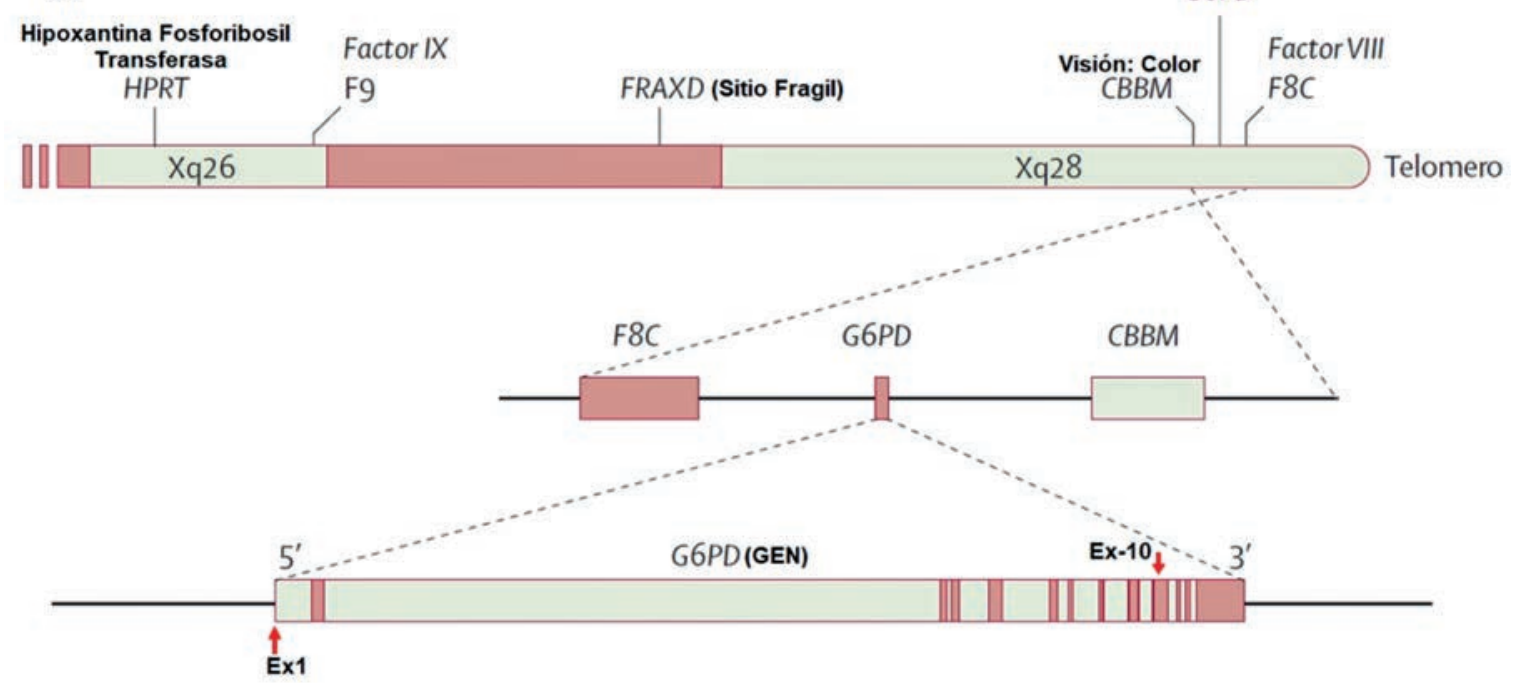

(B)

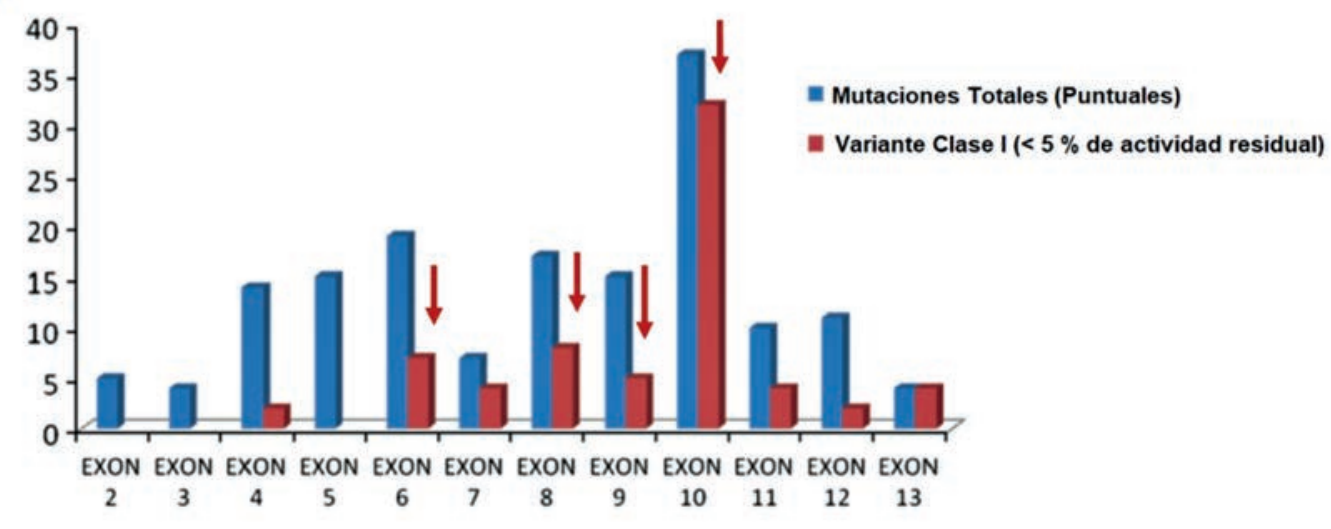

Figura 2. Estructura del Gen de la G6PD y mutaciones Puntuales. (A) Localización génica en el cromosoma X y conformación del Gen, Tomado de Cappellini M. \& Fiorelli G., 2008 (9). (B) Mutaciones puntuales y localización exónica, Tomado de Minucci et al., 2012 (10).

La deficiencia de la G6PD constituye uno de los desórdenes del metabolismo de mayor frecuencia y distribución geográfica a nivel mundial, se documenta una prevalencia mundial de $4,9 \%$ y una población de afectados que sobrepasa los 400 millones de individuos con grados diversos de expresión fenotípica $(11,12)$.

El daño enzimático se relaciona a un síndrome hemolítico inespecífico que se manifiesta en algunos pacien- tes después del tratamiento con algunas drogas o asociadas con el consumo de habas en la dieta (favismo). Se ha observado una alta incidencia en personas de raza negra y algunas poblaciones de judíos, sin embargo, su distribución es panétnica, con una mayor prevalencia en zonas endémicas de malaria (Ver figura 3), estableciendo con este último aspecto, una singular protección a sus portadores frente a esta patología (12-14). 


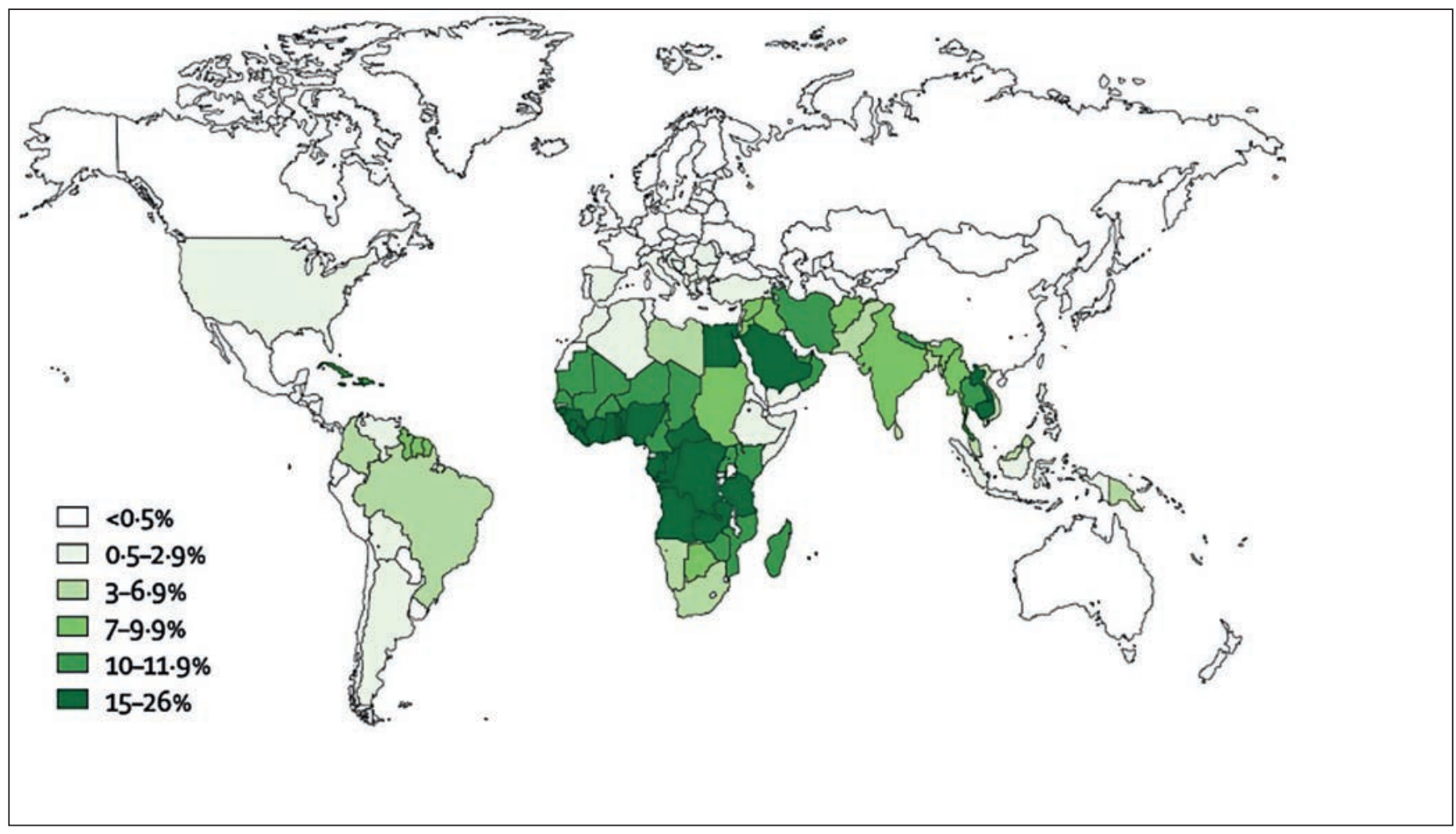

Figura 3. Distribución mundial de la Prevalencia de la deficiencia de G6PD.

Tomado de Cappellini M. \& Fiorelli G., 2008

Bajo la perspectiva histórica, la importancia de la actividad de la G6PD se puso de manifiesto, durante la segunda guerra mundial, en el desembarco de las tropas aliadas, cuando se administró en forma profiláctica el fármaco antipalúdico primaquina a los miembros de las fuerzas armadas. Como consecuencia de ello un número importante de militares, en los que se comprobó posteriormente que existía un déficit de este complejo enzimático, presentaron una anemia hemolítica grave. Estos individuos eran sensibles a diversos compuestos que como la primaquina, generaban estrés oxidativo a nivel globular $(1,15)$. Otros antecedentes importantes muestran que aproximadamente un $10 \%$ de los varones americanos de raza negra a los que se administró el fármaco anterior, durante la guerra de Corea desarrollaron una anemia hemolítica aguda autolimitada. En estos casos, sólo se observó la destrucción de los glóbulos rojos más envejecidos y se estableció que la deficiencia existente en los glóbulos rojos susceptibles era igualmente de G6PD $(1,15)$.

La susceptibilidad hemolitica en individuos afectados con la deficiencia puede aumentar notablemente durante enfermedades intercurrentes o periodos de exposición a di- versos fármacos ó compuestos (p. ej., Primaquina, Sulfamidas, Nitrofuranos y Aminoquinolonas, entre otros) que presentan propiedades oxidativas, sin embargo, la gravedad de la crisis está relacionada con el grado de deficiencia de la enzima $(9,15)$.

Con respecto al grado de compromiso enzimático, como es frecuente en los errores innatos del metabolismo, a medida que se han estudiado las poblaciones afectadas por esta deficiencia, se han documentado grandes diferencias en el porcentaje residual de la actividad enzimática y la gravedad de las manifestaciones clínicas, ejemplifica este aspecto el paralelo entre la severidad encontrada por ejemplo en los asentamientos humanos de origen mediterráneo y la expresión más benigna de la enfermedad en individuos afroamericanos. Estos hallazgos han establecido una clasificación dependiente de la actividad enzimática estandarizada por la organización mundial de la salud que se relaciona a la severidad clínica y el comportamiento enzimático de las enzimas mutadas, que oscila desde las formas clásicas con valores de actividad enzimática $\leq 5$ $\%$ de actividad residual hasta individuos con expresiones limítrofes o comparables a valores de individuos control (Ver tabla 1) $(12,16)$. 
Tabla 1. Clasificación de Variantes de Glucosa 6-Fosfato Deshidrogenasa *

\begin{tabular}{|c|c|c|c|}
\hline Clase & $\begin{array}{c}\% \text { Residual } \\
\text { de Actividad enzimática }{ }^{1}\end{array}$ & $\begin{array}{c}\text { Nivel } \\
\text { de Deficiencia }\end{array}$ & Manifestaciones \\
\hline I & No detectable & Deficiencia Severa & $\begin{array}{c}\text { Anemia Hemolítica esferocíti- } \\
\text { ca, Crónica }\end{array}$ \\
\hline II & $1-10 \%$ & Deficiencia Severa & $\begin{array}{l}\text { Hemolisis aguda inducida por } \\
\text { compuestos o fármacos cau- } \\
\text { sales de estrés oxidativo }\end{array}$ \\
\hline III & $10-60 \%$ & Deficiencia Moderada & Hemolisis aguda ocasional \\
\hline IV ${ }^{3}$ & $60-100 \%$ & Actividad Normal $^{2}$ & Asintomáticos \\
\hline $\mathbf{V}^{3}$ & $\geq 120 \%$ & Sobre- expresión & Asintomáticos \\
\hline \multicolumn{4}{|c|}{ 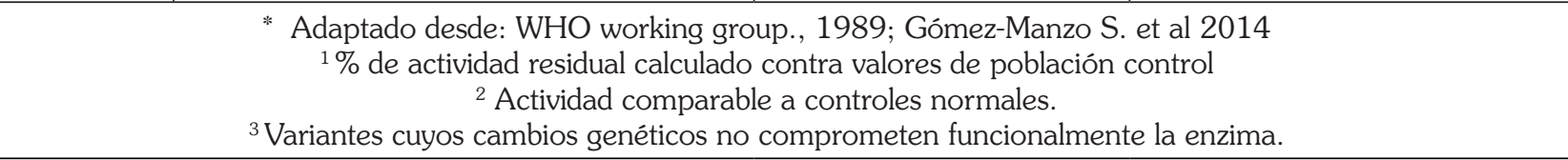 } \\
\hline
\end{tabular}

La presentación clínica, íntimamente ligada al daño estructural y en consecuencia funcional, causada por la mutación, muestra un amplio espectro cuya inespecificidad lo hace con frecuencia indistinguible de otras enzimopatías eritrocitarias, entre las manifestaciones fenotípicas relacionadas a la severidad del episodio hemolítico y la capacidad de compensación celular se encuentran la anemia no esferocítica aguda o crónica, ictericia por una hiperbilirrubinemia de predominancia indirecta (puede progresar a Kernicterus y muerte) y esplenomegalia, entre otros. $(17,18)$

\section{Deficiencia de G6PD en Colombia}

Los primeros estudios en Colombia para la deficiencia de G6PD fueron documentados en la década de los 60s por Arias S. \& Restrepo A., 1966 y Restrepo A. \& Gutiérrez E., 1968, fundamentalmente su investigación estuvo orientada a la descripción de casos y controles mediante los métodos semicuantitativos disponibles para la época, este tamizaje preliminar mostro una mayor prevalencia en individuos afrodescendientes $(19,20)$.

Haciendo una recopilación de toda la literatura formal registrada en Colombia, parecería ser la deficiencia de G6PD el Error Innato del metabolismo más antiguo del que se tenga información confiable sobre estudios de población, sin embargo, es contrastante (Ver revisión de Carmona-Fonseca J. et al., 2008) que los reportes de tamizaje enzimático para esta enfermedad de gran pre- valencia a nivel mundial, sean escasos en Colombia y de muy baja frecuencia en Latinoamérica, más cuando se tiene una población afrodescendiente importante, donde es esperada una prevalencia significativa $(21,22)$.

Este último aspecto, resalta finalmente la importancia del presente documento, dado que muestra una panorámica del tamizaje de alto riesgo para la deficiencia de G6PD durante 22 años en Colombia, utilizando una metodología espectrofotométrica de referencia y reportando el comportamiento enzimático de la población control $e$ individuos con deficiencia parcial ó total de la enzima.

\section{Materiales y Métodos}

\section{Población en estudio}

La experiencia involucró un total de 3837 muestras valoradas en el Centro de Investigaciones en Bioquímica (Universidad de los Andes) durante el periodo 1998 al 2016, en total se analizaron 1801 controles y 2036 individuos (982 hombres/1054 mujeres) remitidos a estudio por anemia hemolítica crónica o episódica de naturaleza no inmune (ver figura 4), Siguiendo las normas para la investigación en salud determinadas en la resolución 8430 de 1993 del ministerio de Salud. 


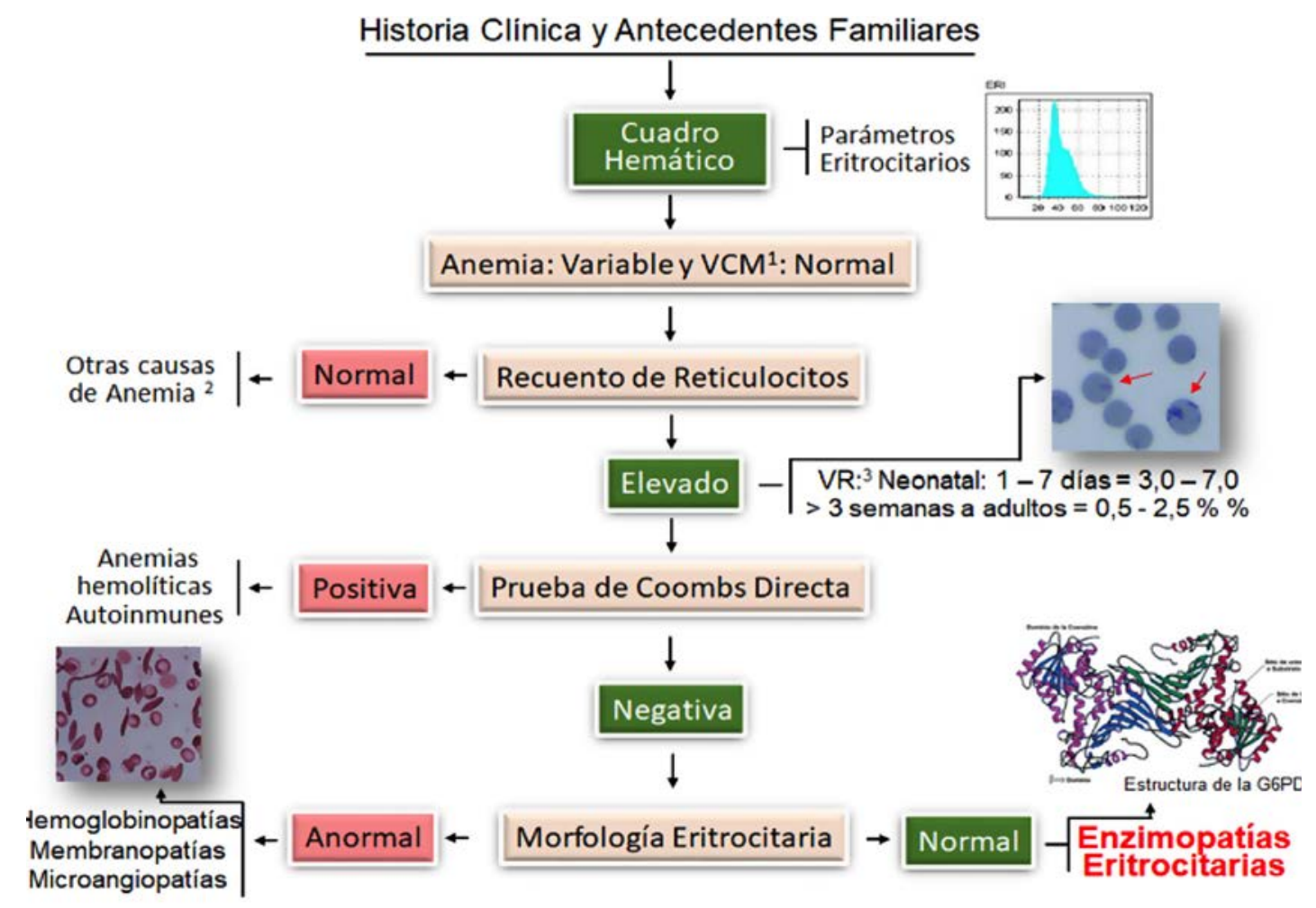

Figura 4. Enfoque global para remisión a estudio de anemia hemolítica no autoinmune. ${ }^{1} V C M$ : Volumen corpuscular Medio, ${ }^{2}$ Otras Causas de Anemia: Ej: Deficiencia de Hierro ó Vitamina B12, Anemia por insuficiencia renal, entre otras. ${ }^{3}$ Documentado por Lilleyman H. \& Blanchette V., 1999 (28). ${ }^{4}$ Imagen adaptada de Cappellini M. \& Fiorelli G., 2008. Flujograma adaptado de Tintinalli et al., 2016. Figura 231-3 (29).

\section{Muestras}

Sangre total: 3 a 5 mililitros de sangre venosa colectados en EDTA $1 \mathrm{mg} / \mathrm{ml}$, la estabilidad máxima reportada para la enzima es de 21 días a $4^{\circ} \mathrm{C}$ (23). La preparación de las muestras para análisis enzimático (Eritrocitos lavados en solución salina isotónica y lisis por choque hipotónico), siguieron los protocolos estandarizados por Bohórquez L., 1990 (24).

4. Ensayo de actividad enzimática

Los ensayos enzimáticos corresponden a un método cinético-espectrofotométrico que permite la valoración simultánea de la G6PD y 6-fosfogluconato deshidrogenasa a 340 nanómetros, mediante el registro de la conversión del cofactor NADP a NADPH llevado a cabo por cada complejo catalítico, Ver figura 5. El protocolo es una adaptación de los experimentos documentados por Bohórquez L., 1990 y Beutler E., 1975,1994 (24-26). La hemog- lobina contenida en la preparación final de cada muestra fue cuantificada por el método comercial de Drabkin (27). La valoración de controles y pacientes fue realizada por duplicado y la actividad final obtenida se expresó en Unidades Internacionales (UI) por gramo de Hemoglobina (HB).

6. Reactivos

El medio de reacción involucra un Buffer Tris (Hidroximetilaminometano) $150 \mathrm{mM} \mathrm{pH:7.5} \mathrm{a}$ partir del cual se prepararon dos componentes de reacción: Reactivo Total (RT): $50 \mathrm{ml} \mathrm{de}$ Buffer que contiene Cloruro de Magnesio 14,95 $\mathrm{mM}$, NADP 0,3 mM, Glucosa-6-Fosfato 1,06 $\mathrm{mM}$ y Acido Fosfogluconico $0,82 \mathrm{mM}$ y Reactivo Parcial (RP): Contiene los mismos elementos citados anteriormente excepto Glucosa-6Fosfato. La estabilidad de los materiales es de 3 meses en congelación $\left(-20^{\circ} \mathrm{C}\right)$. Observación: El Reactivo Total (RT) permite la valoración 


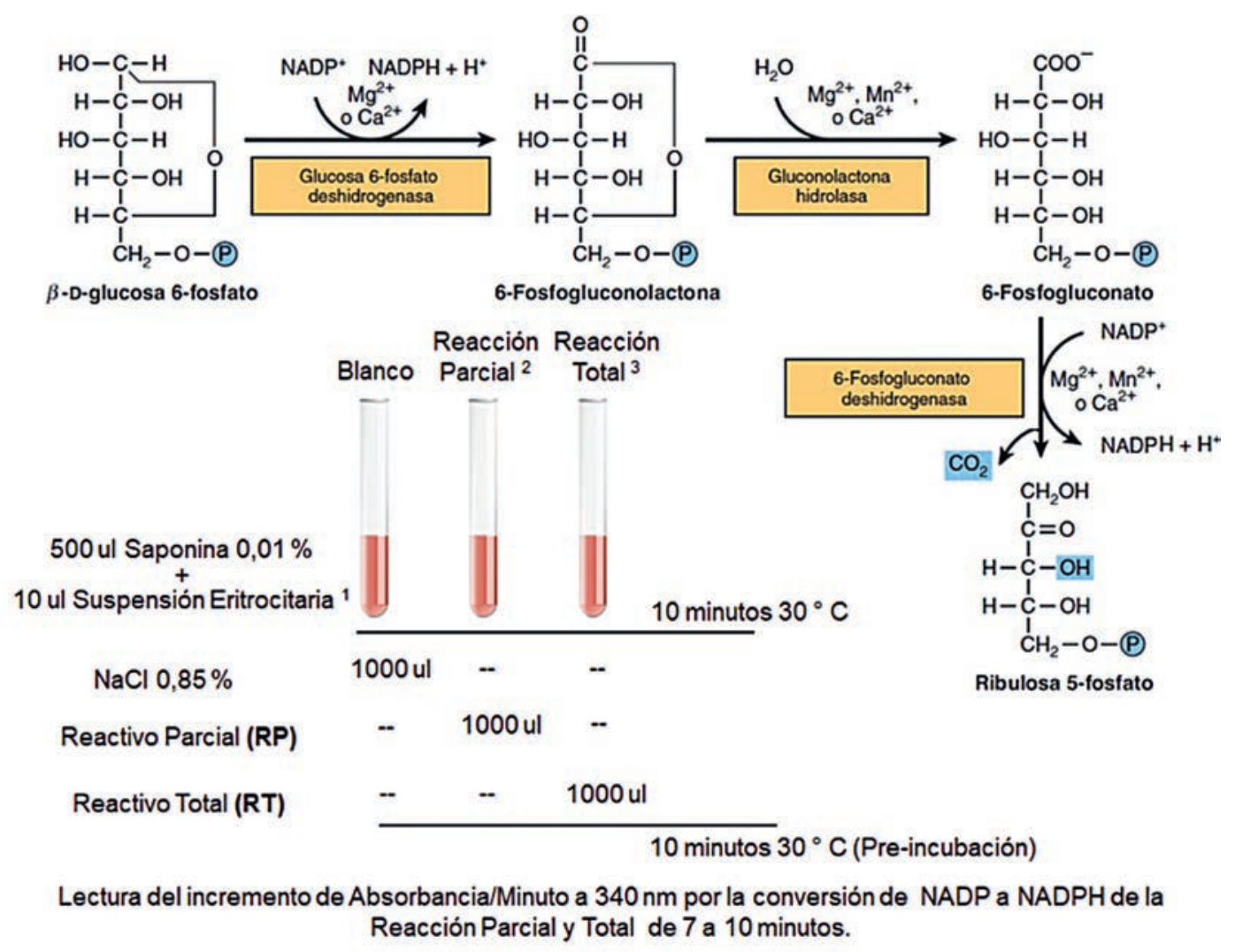

Figura 5. Ensayo cuantitativo de la actividad de G6PD. La reacción se mide en dos fases; el reactivo parcial ${ }^{2}$ que no contiene Glucosa-6 Fosfato permite evidenciar la reacción de la FD, mientras que el reactivo total ${ }^{3}$ que contiene los dos substratos (Glucosa 6-Fosfato y 6-Fosfogluconato), permite valorar la reacción de las dos enzimas. ${ }^{1}$ La suspensión eritrocitaria es una preparación de 250 ul de glóbulos rojos empaquetados y 250 ul de $\mathrm{NaCl}$ al 0,85 \%. Imagen metabólica de fondo adaptada de Bioquímica de Harper: Cap 21: la vía de la pentosa fosfato y otras vías de metabolismo de Hexosas por Murray et al., 2013. Pág. 199 (30).

de la actividad simultánea de la G6PD y la fosfogluconato deshidrogenasa (FD) y el Reactivo Parcial (RP) valora solamente la actividad de la FD, desarrollando in vitro la misma reacción in vivo (Ver figura 5).

\section{Análisis estadístico}

La estadística descriptiva y el análisis general de la casuística fue realizada mediante el paquete estadístico IBM SPSS Statistic 19 provisto por SPSS inc. (Statistical Package for the Social Sciences), (Chigago, EUA). La representación gráfica de los resultados se realizó mediante el software Microsoft Excel @ 2010.

\section{Resultados y Discusión}

Durante el periodo de estudio fueron analizados 1801 controles en un rango de edad de: 1 semana de vida (Periodo Neonatal) hasta 91 años. Los grupos etarios para los análisis descriptivos fueron divididos en $\mathrm{Neo}-$ natos, Lactantes menores (1 a 12 meses), Población pediátrica (1- 14 años) y Mayores a 15 años, siguiendo el comportamiento de los valores hemáticos que muestran los mayores cambios en estos grupos poblacionales (31), sin embargo, la figura 6 muestra una distribución más detallada de la población control estudiada.

Los análisis enzimáticos mostraron un rango de actividad normal para G6PD que incluye a todos los grupos estudiados de 3,31 a 9,98 UI/gramo de HB. La mediana como valor de tendencia central más firme, permitió ver una diferencia significativa en la actividad enzimática entre el grupo Neonatal y la población $\geq 15$ años (Ver Tabla 2). 


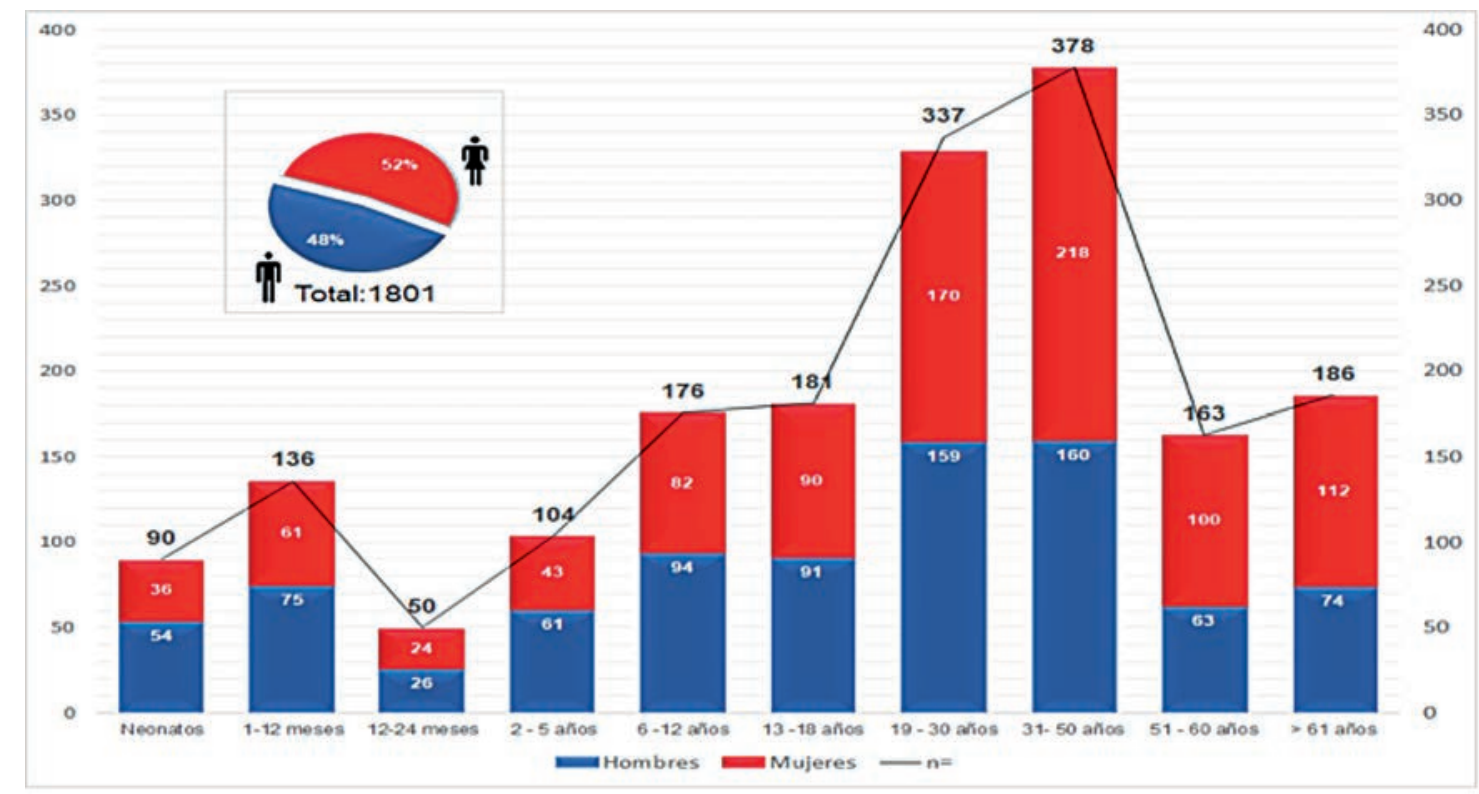

Figura 6. Población Control analizada para G6PD. Los controles del periodo neonatal abarcan individuos de 1 a 3 semanas de vida, a partir de los 15 años se considera un solo grupo control en los análisis estadísticos dado el comportamiento homogéneo de los valores hemáticos (Eritrocitos/Hemoglobina) en este rango de edad.

Tabla 2. Análisis estadístico de la población control.

\begin{tabular}{|c|c|c|c|c|}
\hline \multirow{4}{*}{$\begin{array}{l}\text { Estadística } \\
\text { Descriptiva }\end{array}$} & \multicolumn{4}{|c|}{ Valores de G6PD en Ul/gr de HB } \\
\hline & \multicolumn{4}{|c|}{ Lactantes } \\
\hline & Neonatos & Menores & $1-14$ & $\geq 14,6$ \\
\hline & 1 - 3 semanas & $1-12$ meses & años & años \\
\hline Valor Mínimo & 3,37 & 3,34 & 3,33 & 3,31 \\
\hline Valor Máximo & 9,98 & 8,69 & 9,87 & 9,85 \\
\hline Rango & 6,62 & 5,35 & 6,55 & 6,55 \\
\hline Media & 6,26 & 5,37 & 5,20 & 4,87 \\
\hline Mediana & 6,11 & 5,17 & 4,98 & 4,59 \\
\hline DS & 1,56 & 1,34 & 1,29 & 1,22 \\
\hline Cuartil 1 & 4,98 & 4,23 & 4,18 & 3,97 \\
\hline Cuartil 2 & 6,11 & 5,17 & 4,98 & 4,59 \\
\hline Cuartil 3 & 7,28 & 6,19 & 5,97 & 5,45 \\
\hline Asimetría & 0,38 & 0,62 & 0,84 & 1,28 \\
\hline Curtosis & $-0,41$ & $-0,31$ & 0,29 & 1,80 \\
\hline Percentil-95 & 9,45 & 8,23 & 7,92 & 7,37 \\
\hline$n($ Total $)=1801$ & 90 & 136 & 384 & 1191 \\
\hline
\end{tabular}

Durante los 22 años de tamizaje (1998 - 2016) fueron remitidos a valoración 2036 pacientes cuyo enfoque diagnóstico (Ver Figura 4) orientó los estudios a una anemia hemolítica de posible origen enzimático, un total de 982 varones y 1054 mujeres en un rango de edad de 1 semana a 90 años fueron analizados para
G6PD. El rango de actividad enzimática encontrado oscilo de no detectable $(0,0)$ a $20,0 \mathrm{UI} /$ gr de HB. El tamizaje ofreció 1892 (93\%) casos comparables a los límites de referencia y 144 (7\%) casos con grados variables de deficiencia enzimática (Ver Figuras 7A-B y Tabla 3). 

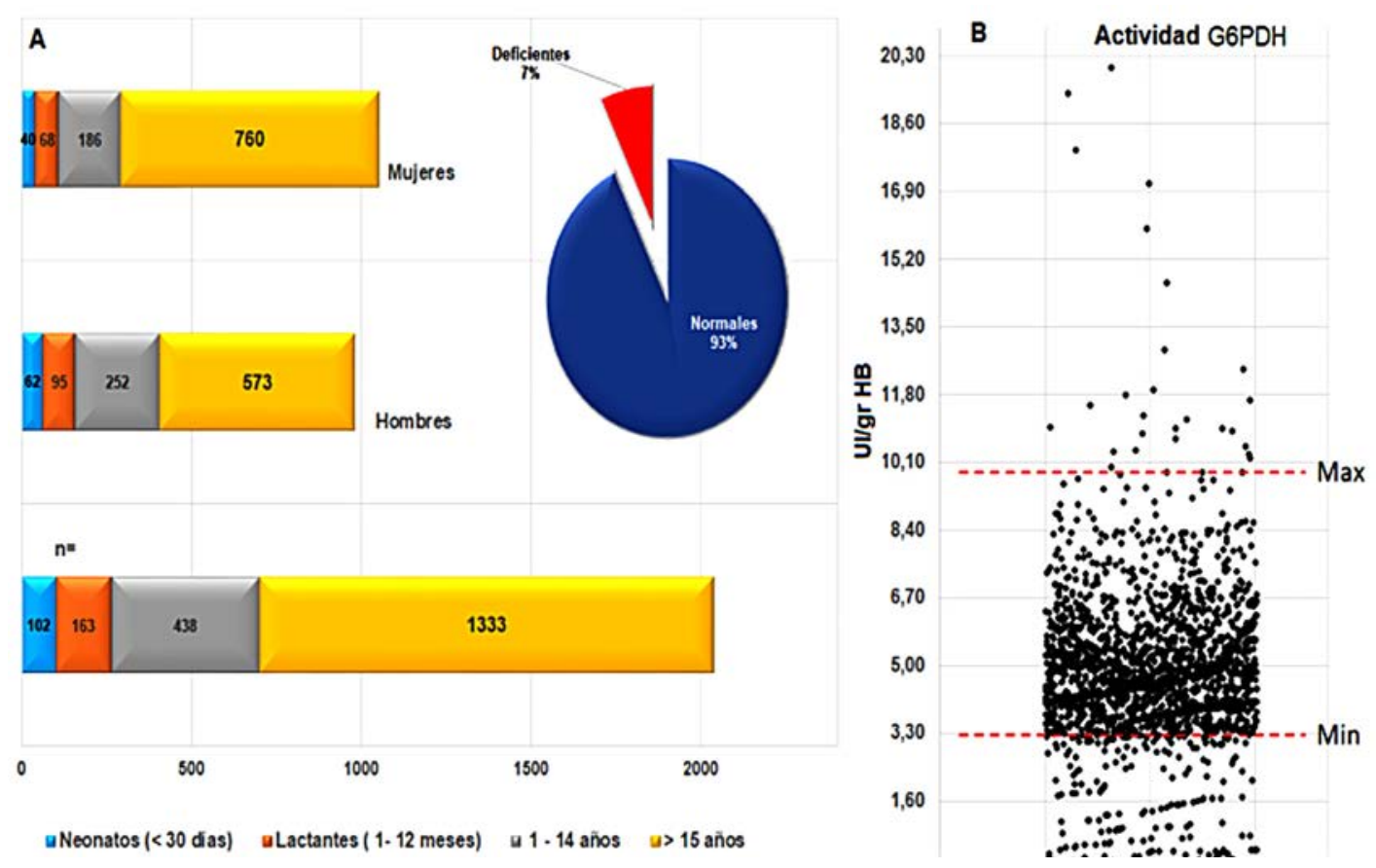

Figura 7. A: Distribución por grupos etarios de la población de alto riesgo valorada para G6PD. B: Distribución de los valores de actividad de G6PD (UV/gr HB) en la población con anemia hemolítica no autoinmune ( $n=2036)$. Los limites máximo y mínimo indicados (línea punteada), corresponden a los límites normales encontrados en los grupos control. El grafico evidencia individuos con deficiencias enzimáticas y sobre-expresiones de actividad.

Tabla 3. Análisis Estadístico de población de alto riesgo en estudio.

\begin{tabular}{|c|c|c|c|c|c|c|c|c|}
\hline \multirow[b]{3}{*}{$\begin{array}{l}\text { Estadística } \\
\text { Descriptiva }\end{array}$} & \multicolumn{8}{|c|}{ Valores de G6PD en UI/gr de HB } \\
\hline & \multicolumn{4}{|c|}{$\begin{array}{l}\text { Población dentro del límite de Referencia * } \\
\text { (n=1892 }-93 \%-) \\
\text { Lactante }\end{array}$} & \multicolumn{4}{|c|}{$\begin{array}{l}\text { Población con deficiencia en G6PD ** } \\
\text { Clase } 1 / \text { III /III }(n=144-7 \%-)\end{array}$} \\
\hline & $\begin{array}{l}\text { Neonatos }{ }^{1} \\
1-3 \text { semanas }\end{array}$ & $\begin{array}{c}\text { Lactante } \\
\text { Menor }^{2} \\
1-12 \text { meses }\end{array}$ & $\begin{array}{l}1-14^{2} \\
\text { años }\end{array}$ & $\begin{array}{l}\geq 14,6^{2} \\
\text { años }\end{array}$ & $\begin{array}{l}\leq 14 \\
\text { años }\end{array}$ & $\begin{array}{l}\geq 14,6^{\text {a }} \\
\text { años }\end{array}$ & $\begin{array}{l}\leq 14{ }^{b} \\
\text { años }\end{array}$ & $\begin{array}{l}\geq 14,6^{\circ} \\
\text { años }\end{array}$ \\
\hline Mínimo & 3,37 & 3,14 & 3,09 & 3,02 & 0,00 & 0,08 & 1,26 & 1,26 \\
\hline Máximo & 19,38 & 11,55 & 17,12 & 20,00 & 1,13 & 1,13 & 2,94 & 2,97 \\
\hline Rango & 16,01 & 8,41 & 14,03 & 16,99 & 1,13 & 1,05 & 1,68 & 1,72 \\
\hline Media & 6,73 & 5,48 & 5,25 & 4,86 & 0,42 & 0,54 & 1,95 & 2,28 \\
\hline Mediana & 6,52 & 5,18 & 4,97 & 4,53 & 0,35 & 0,50 & 1,88 & 2,40 \\
\hline DS & 2,33 & 1,59 & 1,58 & 1,48 & 0,35 & 0,33 & 0,51 & 0,52 \\
\hline Cuartil 1 & 5,11 & 4,21 & 4,15 & 3,91 & 0,08 & 0,25 & 1,51 & 1,71 \\
\hline Cuartil 2 & 6,52 & 5,18 & 4,97 & 4,53 & 0,35 & 0,50 & 1,88 & 2,40 \\
\hline Cuartil 3 & 7,64 & 6,30 & 5,97 & 5,43 & 0,67 & 0,86 & 2,34 & 2,75 \\
\hline Percentil-95 & 10,89 & 8,42 & 8,02 & 7,55 & 1,11 & 1,10 & 2,94 & 2,93 \\
\hline $\mathrm{n}($ Total $)=2036$ & 98 & 136 & 399 & 1259 & 47 & 26 & 23 & 48 \\
\hline \multicolumn{9}{|c|}{$\begin{array}{l}\text { * Se incluye dentro de individuos con sobre-expresión enzimática (100\% de limite superior de población control) } \\
* \star \\
\text { ca agrupación de la población deficiente para G6PD tomando como punto de corte } \geq 14,6 \text { años facilita el } \\
\text { calculo del \% residual de actividad enzimática en razón a que no hay mayores cambios en los valores hemáticos } \\
\text { eritrocitarios (Ver valores promedio de actividad de G6PD en población } \leq 14 \text { años) } \\
\text { a Actividad residual de } 0,0 \text { a } 23 \% \text { b Actividad residual de } 25 \text { a } 66 \% \\
\text { Prueba Shapiro-Wilk: }{ }^{1} \text { Grupo control, Distribución normal } p<0,082,2 \text { Grupos Control, No muestran distribución }\end{array}$} \\
\hline
\end{tabular}




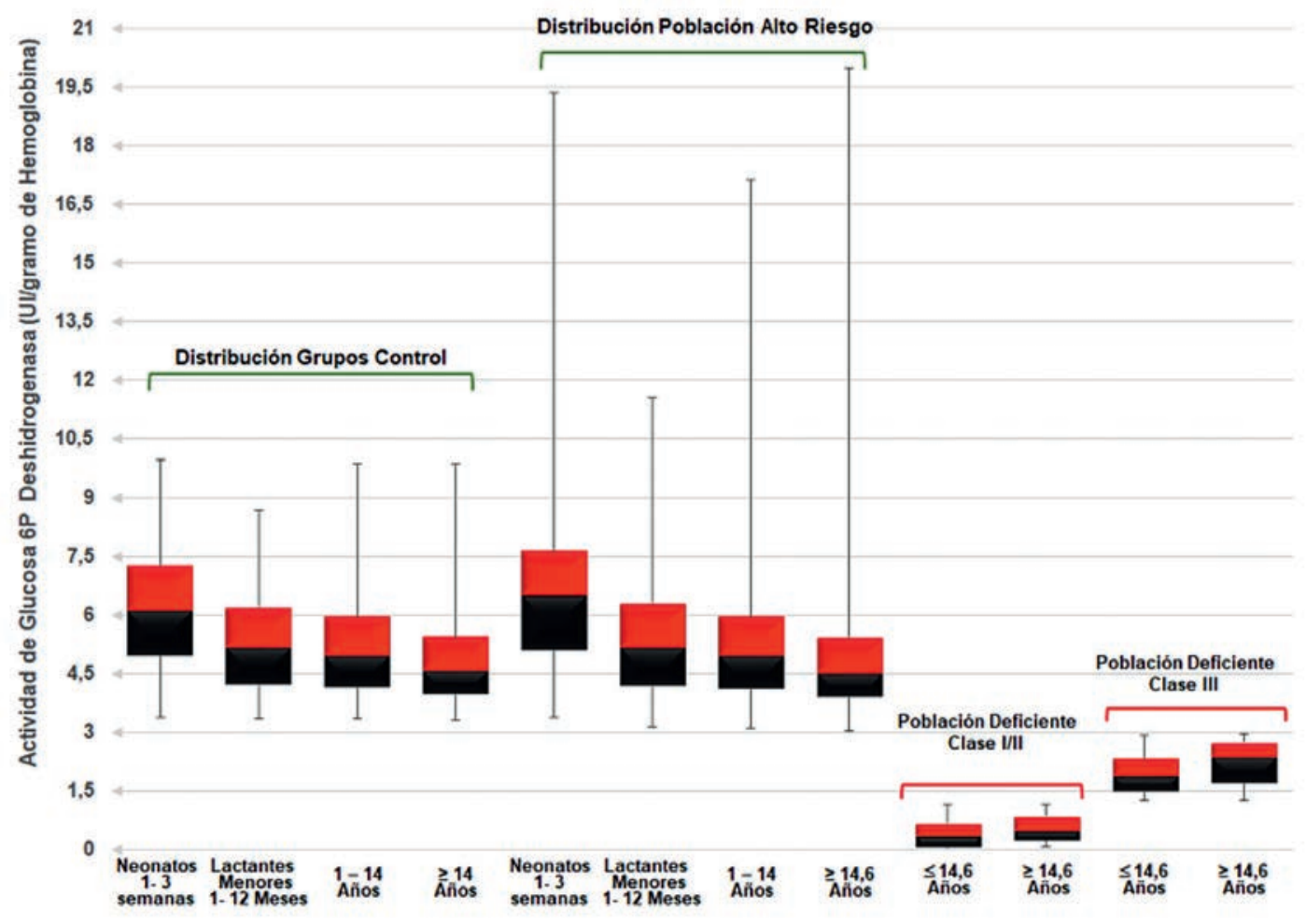

Figura 8. Distribución de la Actividad de la G6PD en los grupos etarios de población control, alto riesgo e individuos con deficiencia enzimática. El punto de división de las dos franjas indica la mediana de actividad enzimática.

El primer cuestionamiento al observar una prevalencia del $7 \%$ se orienta a su valides y a que tan cerca pudiera estar este reporte de ofrecer un valor confiable a la literatura médica colombiana. La respuesta surge necesariamente del tiempo que ha durado el estudio y de la procedencia de los pacientes, que cubre un buen porcentaje del territorio nacional. Sin embargo, este hallazgo no se aleja de lo propuesto por la OMS para Colombia en un reporte preliminar del año 1989 que ubicaba una frecuencia calculada entre $3-7 \%$ (14) y resulta un poco más alto que el promedio mundial de $3,4 \%$ reportado en una amplia revisión de prevalencia en 88 países publicada por Nkhoma E. et al., 2009 (32), un aspecto que puede explicarse por el número de remisiones procedentes del Valle del Cauca, Choco y Antioquia donde la población afrodescendiente y el mestizaje podrían ofrecer una mayor prevalencia de la enfermedad.

Otro aspecto relevante que puede encontrarse en el análisis global de los resultados, se relaciona a que una deficiencia acentuada de la enzima (Clase I y II), no siempre corresponde a presentaciones tempranas de la enfermedad, en razón, a que se tiene individuos afectados con menos de $1 \%$ de actividad que según sus antecedentes clínicos pudieron sobrellevar los primeros años de vida en forma asintomática, un hallazgo que evidencia la importancia del factor desencadenante intimamente ligado al estrés oxidativo (Infecciones, intoxicación, entre otros) que es quien precipita el episodio hemolítico,(33) de ahí que se observen pacientes que mostraron en forma tardía las primeras evidencias de la anormalidad metabólica, aun teniendo una marcada deficiencia enzimática (Ver Figura 8 y Tabla 4$)$.

Los resultados igualmente nos llevan a considerar la deficiencia de G6PD en mujeres que en presente estudio mostró un 33 \% de los casos positivos, la mayoría catalogadas como Clase III (Actividad Residual: 10 - 60 \%) lo que lleva pensar que en su mayoría son heterocigotas para la condición (Ver Tabla 4), un aspecto que invita a un nuevo proyecto orientado a la definición genotípica de esta población. 
Tabla 4. Clasificación de pacientes afectados por deficiencia de G6PD

\begin{tabular}{|c|c|c|c|c|c|c|}
\hline \multirow{3}{*}{$\begin{array}{c}\text { Tamizaje de Alto riesgo } \\
\text { Grupos Etarios }\end{array}$} & \multicolumn{6}{|c|}{ Pacientes Deficientes para G6PD } \\
\hline & \multirow[b]{2}{*}{$\mathrm{n}=$} & \multirow{3}{*}{$\begin{array}{c}\text { Hombres } \\
4\end{array}$} & \multirow{3}{*}{$\begin{array}{c}\text { Mujeres } \\
0\end{array}$} & \multirow{2}{*}{$\begin{array}{c}\text { Clase I } \\
\text { ND ( } 0 \%)\end{array}$} & \multirow{2}{*}{$\begin{array}{l}\text { Clase ॥ } \\
1-10 \%\end{array}$} & \multirow{2}{*}{$\begin{array}{r}\text { Clase III } \\
10-60 \%\end{array}$} \\
\hline & & & & & & \\
\hline Neonatos ( $<30$ dias) & 4 & & & 1 & 1 & 2 \\
\hline Lactantes ( 1 - 12 meses) & 23 & 19 & 4 & 4 & 6 & 13 \\
\hline 1 - 14 años & 43 & 38 & 5 & 4 & 16 & 23 \\
\hline$>15$ años & 74 & 35 & 39 & 0 & 1 & 73 \\
\hline Total $n=$ & 144 & 96 & 48 & 9 & 24 & 111 \\
\hline
\end{tabular}

De importancia igualmente, es el hallazgo de fenómenos de sobre-expresión enzimática identificadas por la OMS como de Clase IV, que en el presente tamizaje corresponde al $1,23 \%(n=25)$, se trata de valores entre 102 al 200 $\%$ del límite superior, un fenómeno que cambia el enfoque del tamizaje que pretende documentar la deficiencia de G6PD. A este respecto se tiene dos interpretaciones muy interesantes relacionadas a la sobre-expresión de actividad, el primero hace referencia a un resultado experimental encontrado por Park J., et al 2006 donde bajo condiciones in vitro demuestra que hay un incremento notable de la actividad enzimática de G6PD, relacionado con el estrés oxidativo enfocado a circunstancias de obesidad y resistencia a insulina. El segundo se presentó en algunos casos donde la anemia hemolítica era causada por otros agentes catalíticos del metabolismo eritrocitario, una situación metabólica que parecería estar relacionada con este incremento de actividad, posiblemente como efecto de compensación a una ruta alterada, hallazgo que continua en investigación.

Finalmente, una última reflexión a los datos obtenidos y la metodología en general, se relaciona específicamente a la prueba de tamizaje aplicada, que dada las condiciones analíticas indicadas anteriormente (Figura 5), simulan totalmente in vitro las condiciones in vivo. Sin embargo a pesar de la especificidad del ensayo enzimático, se han reportado falsos negativos para la prueba, este fenómeno puede presentarse en aquellas variantes cuya actividad residual es bastante alta (Clase III), la anomalía se presenta en la crisis hemolítica que trae consigo un pico en el recuento de reticulocitos, donde la actividad de G6PD sufre una corrección temporal dado que su expresión es mayor en células jóvenes que en células maduras $(9,34)$. Dicha anormalidad se evidenció en el presente tamizaje, donde se registra un caso de un lactante menor de sexo masculino (Edad: 6 meses) clasificado como tipo III, quien mostro en el diagnóstico definitivo una actividad residual para G6PD de 40 \% (2,04 UI/ gramo de Hemoglobina Rango: $3,14-11,55)$ pero quien fue evaluado en crisis hemolítica donde sus valores se ubicaron en el límite inferior de los controles normales.

\section{Conclusiones}

El presente estudio reúne una experiencia de tamizaje de alto riego, en la cual los resultados pueden reflejar un valor medio de la prevalecía nacional relacionada a la deficiencia de G6PD, cuya principal limitación ha sido la remisión de muestras liquidas que requieren cadenas frio en su transporte y que restringe el acceso de poblaciones de riesgo alejadas de las grandes ciudades, a este tipo de pruebas especializadas.

Si se toma los principios de la OMS, que indica la necesidad de realizar un tamizaje en población neonatal a partir de una prevalencia del $3 \%$, Colombia está en mora de instaurar un protocolo a mayor escala para la detección de este desorden del metabolismo eritrocitario, más cuando tenemos regiones con grandes comunidades afrodescendientes, que sin lugar a dudas pueden mostrar prevalencias mayores a las reportadas en el presente estudio. 
¿Cuál es el paso a seguir? Instaurar el análisis de G6PD en muestras de sangre recolectadas en papel filtro, lo que permitiría una mayor cobertura, facilitaría un estudio temprano masivo y la valoración de poblaciones de riesgo alejadas de los centros especializados de análisis, dado que su remisión no requeriría condiciones estrictas de refrigeración. Este cambio mejoraría notablemente la detección temprana y la prevención de graves crisis hemolíticas con sus indeseables consecuencias.

\section{Conflicto de Intereses}

El autor del presente trabajo declara no tener ningún tipo de conflicto de intereses, que invalide la investigación.

\section{Agradecimientos}

Deseo expresar mi agradecimiento a las Directivas de la Facultad de Ciencias y el Departamento de Ciencias Biológicas de la Universidad de los Andes, por facilitar el desarrollo de este proyecto y en forma general el estudio de las enfermedades metabólicas en Colombia.

\section{Referencias}

1. Matthews CK, van Holde KE, and Ahem KG. Biochemistry. 4th edition. Pearson Higher Education. (2013); p. 571-80

2. Van Zwieten, Rob, Arthur J. Verhoeven, and Dirk Roos. "Inborn defects in the antioxidant systems of human red blood cells." Free Radical Biology and Medicine 67 (2014): 377-386.

3. Murray RK, Mayes PA, Granner DK. Bioquímica de Harper 29a Edición. Editorial Manual Moderno. (2012) Pág. 197 - 201.

4. Pardhe BD, Pandey R, Thalquotra M, Singh J, Sodhi KS. Glucose-6-phosphate dehydrogenase deficiency: an update. American Journal Of Pharm Research. 2014; 4(04).

5. Koralkova, P., W. W. Solinge, and R. Wijk. "Rare hereditary red blood cell enzymopathies associated with hemolytic anemia-pathophysiology, clinical aspects, and laboratory diagnosis." International journal of laboratory hematology 36.3 (2014): 388-397.

6. Scriver C.R., Beaudet A.L., Sly W.S., Valle D., et al. The Metabolic \& Molecular Bases of Inherited Disease. Octava Edición. McGraw-Hill. (2001); 3367- 3387

7. Acosta Sánchez Tatiana, Núñez Daniel Pedro, Suárez Luengo Mayelin. Anemia hemolítica por deficiencia de G6PD y estrés oxidativo. Rev Cubana Invest Bioméd [Internet]. (2003) Sep [citado 2017 Sep 20]; 22(3): 186-191. Disponible en: http://scielo.sld.cu/scielo.php?script=s-
ci_arttext\&pid=S0864-03002003000300007\&lng=es.

8. Johnson, Robert M., et al. "The effects of disruption of genes for peroxiredoxin-2, glutathione peroxidase-1, and catalase on erythrocyte oxidative metabolism." Free Radical Biology and Medicine 48.4 (2010): 519-525.

9. Cappellini, Maria Domenica, and G. E. M. I. N. O. Fiorelli. "Glucose-6-phosphate dehydrogenase deficiency." The lancet 371.9606 (2008): 64-74.

10. Minucci, Angelo, et al. "Glucose-6-phosphate dehydrogenase (G6PD) mutations database: review of the "old" and update of the new mutations." Blood Cells, Molecules, and Diseases 48.3 (2012): 154-165.

11. Luzzatto, Lucio, Caterina Nannelli, and Rosario Notaro. "Glucose-6-phosphate dehydrogenase deficiency." Hematology/Oncology Clinics 30.2 (2016): 373-393.

12. Gómez-Manzo S., López-Velázquez G., García-Torres I., et al. Deficiencia de glucosa-6-fosfato deshidrogenasa: De lo clínico a lo bioquímico. Acta Bioquím Clín Latinoam (2014); 48 (4): 409-20.

13. Peters AL, Van Noorden CJ. Glucose-6-phosphate dehydrogenase deficiency and malaria: cytochemical detection of heterozygous G6PD deficiency in women. $\mathrm{J}$ Histochem Cytochem (2009); 57(11): 1003-11.

14. WHO working group. Glucose-6-phosphate dehydrogenase deficiency. Bull World Health Organ (1989); 67: 601-11

15. Beutler, Ernest. "Glucose-6-phosphate dehydrogenase deficiency: a historical perspective." Blood 111.1 (2008): 16-24.

16. Fonseca Dora, Mateus Heidi, Silva Claudia, Contreras Nora, Restrepo Carlos. Deficiencia de glucosa 6-fosfato deshidrogenasa: Aspectos generales de la eritroenzimopatía más frecuente en el mundo. Acta Med Colomb (2005); 30(2): 59-64.

17. Jacobasch G, Rapoprt SM. Hemolytic anemias due to erythrocyte enzyme deficiencies. Mol Aspects Med (1996); 17:143-70.

18. Frank JE. Diagnosis and management of G6PD deficiency. Am Fam Physn. (2005); 72:1277-82.

19. Arias S, Restrepo A. Deficiencia de G6PD en Colombia: valores enzimáticos normales y patológicos en Colombia. Tribuna Médica (1966); 262: 9-12.

20. Restrepo A, Gutiérrez E. The frequency of glucose-6-phosphate dehydrogenase deficiency in Colombia. Am J Hum Genet (1968); 20: 82-5.

21. Carmona-Fonseca Jaime, Álvarez Gonzalo, Ríos Alexandra, Vásquez María Fernanda. Deficiencia de glucosa 6-fostato deshidrogenasa en hombres sanos y en pacientes maláricos; Turbo (Antioquia, Colombia). Rev. bras. epidemiol. [Internet]. (2008) June [cited 2017 Sep 22] ; 11( 2 ): 252-265. Available from: 
http://www.scielo.br/scielo.php?script=sci_arttext\&pid=S1415-790X2008000200007\&lng=en. http:// dx.doi.org/10.1590/S1415-790X2008000200007.

22. Ramírez-Cheyne J, Zarante I, Deficiencia de glucosa-6-fosfato deshidrogenasa: situación actual, su relación con malaria y estrategias para calcular su prevalencia. Universitas Médica (2009) 5058-76. Disponible en: http:// www.redalyc.org/articulo.oa?id=231018725005. $\mathrm{Fe}$ cha de consulta: 22 de septiembre de 2017.

23. Castro, S. M., Weber, R., Dadalt, V., Santos, V. F., Reclos, G. J., Pass, A., and Giugliani, R. Evaluation of glucose-6-phosphate dehydrogenase stability in blood samples under different collection and storage conditions. Clin. Chem. 51, (2005): 1080-1081.

24. Bohórquez Luisa F. Caracterización cinética y electroforética de Glucosa-6-fosfato Deshidrogenasa en una población colombiana. [disertación] Bogotá (Colombia). Universidad de los Andes. 1990.

25. Beutler, E. Red cell metabolism: a manual of biochemical methods. 2nd ed. New York: Grune \& Stratton. (1975); p.66-69

26. Beutler, E. "G6PD deficiency." Blood 84.11 (1994): 3613-3636.

27. Drabkin, D.L., and Austin, J.H., Spectrophotometric studies. II. Preparations from washed blood cells; nitric oxide hemoglobin and sulfhemoglobin. J. Biol. Chem.,
112, 51 (1935).

28. Lilleyman J, Hann I, Blanchette V (Eds) Pediatric Hematology. London: Churchill Livingstone, (1999), 23-49.

29. Ray, John C., and Robin R. Hemphill. "Anemia." Tintinalli's Emergency Medicine: A Comprehensive Study Guide, 8 e Eds. Judith E. Tintinalli, et al. New York, NY: McGraw-Hill, 2016.

30. Murray RK, Mayes PA, Granner DK. In: Bioquímica de Harper 29a Edición. McGraw-Hill, (2013); Cap 21. p.199.

31. Campuzano G. Del hemograma manual al hemograma de cuarta generación. Medicina \& Laboratorio (2007); 13: 511-550.

32. Nkhoma, Ella T., et al. "The global prevalence of glucose-6-phosphate dehydrogenase deficiency: a systematic review and meta-analysis." Blood Cells, Molecules, and Diseases 42.3 (2009): 267-278.

33. Park, Jiyoung, et al. "Increase in Glucose-6-Phosphate Dehydrogenase in Adipocytes Stimulates Oxidative Stress and Inflammatory Signals." Diabetes 55.11 (2006): 2939.

34. Mesner O, Hammerman C, Goldschmidt D, Rudensky B, Bader D, Kaplan M. Glucose-6-phosphate dehydrogenase activity in male premature and term neonates. Arch Dis Child Fetal Neonatal (2004); 89: F555-7 